To the Editors:

\title{
Yet another form of child abuse?
}

The provocation to write this letter was when I came across a 2-week old baby admitted to our unit was found to have pyogenic meningitis. He had been initially treated for fever by a general practitioner with a diclofenac sodium suppository (Voltaren) 2 days before admission, which delayed appropriate treatment. The use of diclofenac sodium (Voltaren) suppositories in paediatric practice has almost reached epidemic proportions (1). Some mothers carry it in their handbags instead of popular brands of paracetamol!

Diclofenac sodium suppositories are not licensed in Sri Lanka to be used as an antipyretic in children; neither is it registered in the UK for use as an antipyretic (2). It is known to cause rectal irritation, and some children present with bleeding per rectum after such use (2). The objective of this letter is to sensitise the medical profession regarding the abuse of Voltaren suppositories in the treatment of childhood fever.

\section{References}

1. de Silva SG. The past and the future. Sri Lanka Joumal of Child Heallh 2000; 29: 1-2.

2. British National Formulary. Diclofenac sodium. British Medical Association and Royal Pharmaceutical Society of Great Britian, 2000; 40: 256-7.

Sanath P Lamabadusuriya, Professor and Head, Department of Paediatrics, Faculty of Medicine, University of Colombo. 